\title{
A teoria das representações sociais na pesquisa interdisciplinar*
}

\author{
Josie Agatha Parrilha da Silval \\ Universidade Estadual de Ponta Grossa
}

$\mathrm{E}$ ste trabalho é um comentário sobre a proposta de estudo da teoria das Representações Sociais, apresentada por Serge Moscovici², em especial pelo livro "Representações Sociais: investigações em psicologia social" (MOSCOVICI, 2007). O estudo foi realizado em uma das disciplinas do Programa de Pós-Graduação em Educação para a Ciência e a Matemática ${ }^{3}$ (UEM). O primeiro passo para a análise da obra foi buscar o entendimento do contexto no qual foi escrito, bem como o de seu escritor. Para tanto, procurou-se responder a essas questões: Quem é Moscovici? Em que contexto escreveu este livro? O que animou sua obra, ou seja, que problema ou problemas buscou responder? Algumas destas questões podem ser respondidas mesmo antes de iniciarmos a leitura do livro, outras, apenas com sua completa análise. O autor estudou mecânica filosofia, psicologia e epistemologia da história das ciências e iniciou a vida acadêmica na década de 1960, sendo, atualmente, diretor do Laboratoire Européen de Psychologie Sociale. Moscovici foi o responsável pela introdução do termo "Representações Sociais", na década de 70, termo este, que passou a ser adotado na psicologia social de toda Europa, bem como em outras partes do mundo.

O livro foi organizado desta forma: introdução e sete capítulos, assim nominados: "O fenômeno das Representações Sociais": "Sociedade e teoria em psicologia social"; "A histórica e a atualidade das Representações Sociais"; "O conceito de themata"; "Caso Dreyfus, Proust e psicologia social"; "Consciência social e sua historia"; "Idéas e seu desenvolvimento - um diálogo entre Serge Moscovici e Ivana Marková”. A introdução do livro foi realizada por Gerard Duveen, que procurou explicitar sobre as Representações Sociais, seus conceitos e sua relação com a psicologia social e sociologia. O texto apresenta, de forma resumida, o caminhar intelectual de Moscovici dentro deste estudo e relaciona as Representações Sociais com a psicologia social.

\footnotetext{
* Theory of the social representations in the interdisciplinary research

${ }^{1}$ Endereço para correspondências: Universidade Estadual de Ponta Grossa, Av. General Carlos Cavalcante, 4748, Campus Uvaranas, Bloco de Artes, Ponta Grossa, PR, 84030-900 (josieaps@ @otmail.com). Agradecimentos: Programa de Educação para a Ciência e a Matemática e Fundação Araucária.

${ }^{2}$ Serge Moscovici (1925- ), psicólogo social que nasceu na Romênia. Atualmente, ele é diretor em Paris da École dês Hautes Étules em Sciences Sociales e diretor do Laboratoire Européen de Psychologie Sociale . É membro da Academia Européia de Ciências e Artes e Oficial da Legião de Honra, assim como membro da Academia Russa de Ciências e membro honorário da Academia Húngara de Ciências. ${ }^{3}$ Disciplina "As representações sociais - teoria e aplicação às ciências e educação científica", ministrada por Luzia Marta Bellini, Regina Pavanello e Patrícia Lessa.
} 
E, ao situar as Representações Sociais de Moscovici, dentro do conjunto de sua obra, assinada para um novo estudo que desponta: a psicologia social genética.

E, na sequiência dos capítulos, Moscovici apresenta suas idéias sobre as Representações Sociais. Explicita que as representações apresentam duas importantes funções: convencionalizar e prescrever objetos, pessoas ou acontecimentos. Tais representações são diferentes em cada sociedade, ao mesmo tempo em que as ultrapassam. Discute sobre o campo da psicologia social na Europa, destacando as contribuições dos Estados Unidos nessa área. Para ele, os norte-americanos contribuíram na área, por serem mais preocupados com a sua própria realidade, ou seja, mais ligados a essência da psicologia social do que os europeus, que procuram ter uma visão mais ampla da sociedade e não se focam nos problemas sociais mais simples. Destaca, ainda, o importante papel dos os psicólogos europeus deveriam ter para as ciências sociais e para a sociologia, o que na prática não ocorria (MOSCOVICI, 2007).

Moscovici aborda o significado de Representações Sociais, elucidando que estão sempre inscritas dentro de um "referencial de um pensamento preexistente" e, com isso, são dependentes de sistemas de crença ancorados em "valores, tradições e imagens do mundo e da existência". Retoma a importância de se ultrapassar do microsociológico para o macrosociológico, por meio de uma teoria que se adeque a esta relação. Ele apresenta o conceito de "themata", que em seu sentido exato, que o latim significa "o que está colocado ou o que é", todavia, aponta que este conceito é um desdobramento teóricoepistemológico do conceito de Representações Sociais. No "Caso Dreyfus, Proust e a Psicologia Social", discutido no quinto capítulo do livro, apresenta o caso Dreyfus, um importante marco referencial para a psicologia social. Nessa discussão entra em debate a "consciência coletiva", de acordo com o conceito apresentado por Durkheim. O autor apresenta, ainda, um importante estudo sobre dois importantes estudiosos: Piaget e Vygotsky - explicitando que os dois autores apresentavam mais coisas em comum do que divergentes, ao abordarem questões da psicologia, em especial, nos estudos do desenvolvimento mental humano. No último capítulo, Moscovici aponta que não quer discutir sobre a diferença entre "coletiva" e "social", pois, não considera essa questão tão importante quanto às idéias que trazem com seu entendimento que, mesmo sendo do cotidiano ou variável em cada sociedade, são também universais (MOSCOVICI, 2007).

Como uma das questões principais do livro, encontra-se a intenção de apresentar em que consistem as Representações Sociais. Entre as muitas explicações de Moscovici (2007; p. 210), ressalta-se esta: “[...] ponto de visa dinâmico, as Representações Sociais se apresentam como uma rede de idéias, metáforas e imagens, mais ou menos interligadas livremente e, por isso, mais móveis e fluidas que teorias." Para o autor as Representações Sociais têm 
como intenção converter algo desconhecido em conhecido, pois tudo que é desconhecido e não faz parte do dia a dia é difícil de ser aceito. Desta forma, para que este "desconhecido" se torne conhecido é necessário que se processe uma transformação, tal transformação é realizada pelo grupo, ao vincular imagens concretas e compreensíveis do seu dia a dia aos novos esquemas conceituais que surgem. Para Moscovici são utilizados dois meios para tornar este "desconhecido" em "conhecido", a objetivação e a ancoragem. A ancoragem é entendida como uma forma de classificar ou dar nome a "alguma coisa" e, objetivar, é entendido como a transformação de algo abstrato em algo mais concreto ou, ainda, como a transformação de algo que está na mente em algo do mundo real. A objetivação visa transformar algo que está no nível abstrato, desconhecido para outro, mais acessível, tornando-o mais concreto e objetivo. $\mathrm{E}$, as duas operações essenciais da objetivação são: naturalizar e classificar. Já a ancoragem ajuda a ligar o que é estranho ao grupo a alguma representação social existente, sendo que classifica e nomeia o desconhecido, todavia, este processo não é neutro, o novo elemento é posicionado como positivo ou negativo, de acordo com o que é conhecido pelo grupo. Estes dois conceitos: ancoragem e objetivação, apresentados por Moscovici, são fundamentais para o entendimento de Representações Sociais (MOSCOVICI, 2007).

O livro apresentou o caminho intelectual de Moscovici (2007; p.208), que assim resume o seu entendimento de representações: "elas são formadas através de influências recíprocas, através de negociações implícitas no curso das conversações, onde as pessoas se orientam para modelos simbólicos, imagens e valores compartilhados específicos". Ressalta-se a existência de dificuldades no entendimento dos conceitos apresentados, especialmente devido a sua complexidade, bem como, por não se enquadrar em uma única área, uma vez que se liga especialmente a psicologia e a sociologia. Assim, destaca-se a importância das Representações Sociais para estudos que não se limitam a uma única área e sim, que procuram compreender o homem e a sociedade em sua multiplicidade e complexidade (MOSCOVICI, 2007).

As idéias de Moscovici fundamentam muitos estudos e analises de casos, entre estes, encontra-se o texto Hélène Joffe ${ }^{4}$ (1994), "Eu não, não o meu grupo. O texto aponta que, ao se tratar de doenças incuráveis, é comum que as pessoas respondam: "Eu não", "o meu grupo não", ou seja, que considerem a doença como distante de si e do seu grupo. Joffe discute as Representações Sociais elaboradas a partir dos dados levantados na pesquisa sobre a AIDS. Descreve qual o processo de ancoragem realizado pelos grupos e qual o núcleo central, destacando que as Representações Sociais da AIDS são ancoradas em ideologias da sociedade e, a objetivação da AIDS, em certos lugares, práticas e grupos.

${ }^{4}$ Professora da Univertity College of London e especialista em teoria das Representações Sociais. 
Por fim, na conclusão, Joffe destaca que a disseminação da AIDS é vista como responsabilidade de um grupo externo, isso porque o grupo elabora um mecanismo de defesa que o afasta o grupo do risco e, ainda, propicia a sensação de controle. Desta forma, a construção da representação social relaciona-se ao medo e a defensiva (crise). A AIDS apresenta-se ligada a uma condição do "outro" e a uma condição "estrangeira", como meio de defesa, que afasta a ameaça inserida pela AIDS ao 'eu' ou ao 'meu grupo' e centra seu olhar sobre o 'outro', “ameaçado e ameaçador” (JOFFE, 1994).

O texto de Joffe analisou as Representações Sociais da AIDS, com questões sobre origem do HIV/AIDS, a disseminação da doença e quais grupos eram mais afetados pela doença. Nos diferentes grupos observou-se a projeção da responsabilidade pela AIDS para grupos externos ao seu próprio grupo. Tais projeções demonstraram a relação entre sentimentos como medo, nas representações da ameaça da doença. Joffe relaciona esta projeção da doença ao outro com os primeiros anos da infância e do processo projetivo de defesa utilizado desta fase (JOFFE, 1994).

Ao relacionar o texto de Joffe com as ideias de Moscovici apresentadas no livro, observa-se que existe uma sintonia entre ambos. A pesquisa apresentada no texto assemelha-se a um exemplo da teoria apresentada por Moscovici, e, o processo de objetivação e ancoragem, é avistado na pesquisa sobre o HIV/ AIDS, sendo sua ancoragem "uma praga". Com essa ancoragem, pode-se objetivar a doença mais próxima da realidade do grupo e esta pode ser classificada como uma doença de determinados lugares, práticas ou grupos. Após a ancoragem, na objetivação, a AIDS foi classificada e foram elaboradas algumas explicações sobre sua propagação pelos entrevistados. Surgiram histórias ou mitos sobre a doença, como por exemplos: ter sido transmitida pela relação sexual entre homem-macaco; disseminação de uma arma química de países desenvolvidos. No texto, observa-se além dos conceitos empregados por Moscovici sobre a representação social, a ligação entre mecanismos psicológicos e sociais. Tais representações incluem questões emocionais, não no sentido individual, mas de mecanismos que todo ser humano tem em comum. Sugere, ainda, que a pesquisa procura trilhar um novo estudo, apresentado no livro de Moscovici como "psicologia social genética".

Desta forma, a análise do livro de Moscovici propiciou alguns questionamentos, como a apresentada no início do texto: "O que animou sua obra, ou seja, que problema ou problemas buscou responder?". A esta questão responde-se que, no livro, observou-se que o autor procurou responder algumas questões sobre os fenômenos das Representações Sociais e, para tanto, organizou algumas de suas principais idéias e conceitos. Bem como, apresentou-se o caminho intelectual de Moscovici, que assim resume o seu entendimento de representações: "elas são formadas através de influências recíprocas, 
através de negociações implícitas no curso das conversações, onde as pessoas se orientam para modelos simbólicos, imagens e valores compartilhados específicos" (MOSCOVICI, 2007; p.208).

Compreende-se o importante papel que o autor e esta obra têm para esta nova linha de estudos das ciências sociais, as Representações Sociais. Mesmo que novas discussões sejam apresentadas nesta área, é importante a leitura desta obra, fonte primária e base deste campo de estudos. Ressalta-se a existência de dificuldades no entendimento dos conceitos apresentados, especialmente devido a sua complexidade, bem como, por não se enquadrar em uma única área, uma vez que se liga especialmente a psicologia e a sociologia. Após séculos de tradição de divisões nas áreas de conhecimento, os estudos do final do século XX e inicio do XXI, apresentam propostas de entrelaçamento entre as diferentes áreas. Tal questão pode ser exemplificada estudos atuais que utilizam termos como interdisciplinar, transdisciplinar, hibridismo, entre outros. As Representações Sociais podem contribuir com estudos que não se limitam a uma única área e sim, procuram compreender o homem e a sociedade em sua multiplicidade e complexidade. Desta forma, a teoria das Representações Sociais, pode ser um referencial possível para trabalhos de pesquisa interdisciplinar.

\section{Referências bibliográficas}

JOFFE, H. Eu não, meu grupo não: Representações Sociais transculturais da Aids. In: JOVECHLOVITCH, S. \& GUARESCHI, P. (Orgs.) Textos em representação. Petrópolis: Editora Vozes, 1994.

MOSCOVICI, S. Representações sociais: investigações em psicologia social.

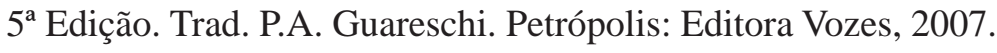

